\title{
Effect of thermal induced stress of concrete on performance characteristics of constructions
}

\author{
Ivan Pulyaev *, Sergey Pulyaev, Yuri Bazhenov, Anna Fetisova and Olga Shcherbeneva \\ Moscow State University of Civil Engineering, Yaroslavskoe shosse, 26, Moscow, 129337, Russia
}

\begin{abstract}
The article discusses issues related to determining and taking into account own thermally stressed state, which is formed in concrete during hardening, and is used to provide the required consumer properties of concrete during the construction of the Crimean bridge. It's relevant in view of the tight construction timeframe for the said facility in rough terrain and hot climate. It is known that the location of a massive object in salty seawater, a hot climate, an increased seismic hazard, the presence of ice loads in the winter period of time, a large strait depth and other factors required a serious approach to ensuring the quality of concrete work and increasing the durability of the structure. The paper presents the results of own thermally stressed state of hardening concrete when determining the permissible temperature gradient in it, which made it possible to speed up the process of building the object while observing the necessary properties. This question seems relevant due to short deadlines, construction of the specified facility in adverse conditions, and also taking into account the development in our country construction of unique non-class objects.
\end{abstract}

\section{Introduction}

The Crimean Bridge is one of the most ambitious projects currently being implemented in our country. Its construction began in 2015, and in May 2018, traffic on the road section of the bridge started. Currently, intensive construction of the railway part of the bridge, the deadline for which is scheduled for the end of 2019, is continuing. It is known that complex technical and operational factors required a serious approach to ensuring the quality of concrete work and increasing the durability of this structure. Particularly important condition is the fulfillment of these requirements to ensure high consumer properties in conditions of accelerated rates of construction of the facility, which is justified by the great socio-economic importance of the bridge.

To this end, in the process of developing technical documentation, it was necessary to envisage measures aimed at reducing the crack resistance of the structure at a given rate of concrete work. One of the most important properties of cement, affecting the quality of concrete work, is its heat dissipation, which must be taken into account when conducting the whole complex of works $\left[\begin{array}{ll}1 & \ldots\end{array}\right]$. In addition, from the experience of building many artificial structures, it is known [5 ... 9] that due to undercounting of the temperature factor, when designing in concrete, numerous defects and cracks may appear, which require

*Corresponding author: ivanes50@mail.ru 
significant funds to be eliminated and take a long time. The same experience shows that this should also take into account temperature microstresses in the material (concrete) and macrostresses in the structure itself, as the basis of measures prevent the occurrence of cracks in concrete due to temperature changes in it. These principles were the basis for decisions to ensure high consumer properties of concrete of the object in question, the main of which are presented for consideration in this article.

\section{Methods}

For reinforced concrete transport structures, traditionally, there are increased requirements to ensure basic technological properties of concrete. In order to ensure compliance with these requirements, it is necessary to strictly control the quality characteristics and properties of the concrete mix, the process of laying it in the formwork and ensuring the required care for hardening concrete in the process of gaining strength. And if the control of the first two criteria is currently debugged quite well $\left[\begin{array}{ll}10 & \ldots 11\end{array}\right]$, then, as practice shows, taking care of concrete in the process of hardening during the summer period of time most often consists only in maintaining the temperature regime acceptable by regulatory documents and controlling the required temperature gradient in the process of gaining concrete strength, as well as in the process of removing the formwork system. However, practical experience shows the fallacy of this formulation of the question [12] due to the fact that in the process of leaving one should first take into account various types of temperature stresses formed in the process of concrete hardening: microstress, macro stress, as well as its own thermally stressed state. Consider these types of voltages in more detail.

Thermal microstresses are understood to be the voltages that occur in hardening bake due to:

- differences in linear thermal expansion coefficients and moduli of elasticity of a large filler and hardening cement mortar (microstress of the first kind);

- differences of linear temperature expansion coefficients and elastic moduli of fine aggregate and cement stone (microstrain of the second kind);

- differences in the coefficients of linear thermal expansion and the moduli of elasticity of individual cement stone crystals (microstrain type III);

These stresses significantly affect the amount of permissible elasticity of concrete, depending on the temperature value at which the spatial crystallization structure of $3 \mathrm{CaO}_{2} \mathrm{SiO}_{2} 3 \mathrm{H}_{2} \mathrm{O}$ in hardening cement stone is formed at the time of concrete gaining 25 ... $30 \%$ of the strength at 28 days of age $\left(\mathrm{R}_{28}\right)$.

Practice shows that the higher the temperature at which the concrete mix hardens, the greater is the amount of microstresses in it when the temperature gradient of the outside air changes [13]. By temperature macrostresses we mean the stresses arising in the hardening concrete of a structure with a direct change in the temperature gradient in it over time. It should be noted that in concrete structures, along with the temperature stresses described above, there are residual (proper) stresses. These stresses are macrostresses that are present in the concrete mixture during its curing at the time of uniform distribution of temperatures throughout. Practice shows [14] that the indicated stresses can increase or decrease the crack resistance of the whole structure, which means that the stresses that increase the crack resistance of the structure are called favorable, and the lowering it - unfavorable. The nature of own thermally stressed state is determined by the temperature curve of zero voltages, which is understood as the temperature distribution in the structure, with which there are practically no such voltages.

Based on studies of the physicochemical processes occurring during the formation of cement stone, carried out at the Research Institute of Transport Construction, and confirmed by unique experiments performed at the Technical University of Munich, it was 
found that during the formation of the zero-temperature temperature curve, time should be taken formations in a cement-hardening stone of a spatial crystallization structure of $3 \mathrm{CaO}_{2} \mathrm{SiO}_{2} 3 \mathrm{H}_{2} \mathrm{O}$ in the layer with the greatest lag in the process of hydration of cement, which corresponds to $t$ the transition time of concrete in the elastic state.

To begin, consider the case when a thin overlap is heated from each side separately. In this case, the blendless mixture passes into the elastic material first in the outer layers and, as a result, they can freely "move" relative to each other as long as there is a layer of loose concrete mixture between them. With the interconnection of two opposite layers, the overlap begins to work as a whole and the temperature distribution at the moment of the layers joining is taken as the temperature curve of zero voltages, and the indicated time during the formation of its own thermally stressed state. In this case, a concave (unfavorable) temperature field of zero stress is created, since when leveling over the volume of overlap, the surface more heated layers will have greater temperature stresses than the internal layers, which in turn will impede the free movement of the outer layers, which will cause the surface layers to become "stretched" when leveling the temperatures along the overlap array and less crack resistant than internal.

Next, we consider the case of internal heating of concrete (for example, when maintaining the overlap by the "thermos" method). In this case, the concrete mix in the inner layers will quickly gain the required strength, and in the future the surface layers will be less heated than the stretched inner ones, which will "restrain" the stretching of the outer layers. In this case, a convex zero-temperature temperature field is created, indicating the formation of a favorable own thermally induced state.

Based on the above, it is worth noting that taking into account the processes described above makes it possible in real conditions to significantly increase the value of the allowable temperature difference in concrete when it is heated and cooled (up to $40 \ldots 50^{\circ} \mathrm{C}$ against the usually accepted $20^{\circ} \mathrm{C}$ ), which generally ensures high consumer properties of the structure, including the provision of the required period of its construction.

To determine the conditions for the formation of a thermal stress-induced state in a hardening concrete structure, it is necessary to carry out physical modeling of the thermophysical processes of hardening concrete of this structure [ $\left[\begin{array}{lll}15 & \ldots & 18\end{array}\right]$ using computational-analytical software systems and determine the allowable temperature difference over its cross section taking into account the requirements described above. In the present work, the authors used the software-analytical complex ZA010, in which the heat transfer processes of the studied area are based on the system of equations for heat energy balances, in which the area under study is divided into a finite number of microelements and in the future their thermal interaction with each other and with the environment is considered. The effect of temperature on the processes occurring during cement hydration is taken into account by the reduced time hypothesis. The calculations involve the use of real compositions of the concrete mix, as well as data on the temperature of the laid concrete mix and outside air. The reliability of the calculation results is ensured by proper assignment of the elastic modulus of concrete, provided that the elastic stresses in it are directly proportional to the elastic modulus, and in consideration of changes in the plastic properties of concrete during cement hydration and creep manifestation under the influence of the applied load. All of these parameters were fully taken into account in the construction of the Crimean Bridge, and the results obtained are presented below.

\section{Results}

When carrying out thermophysical calculations of hardening concrete, the following structural elements were considered: grillages, bodies, pillars, crossbars, as well as a monolithic reinforced concrete superstructure with the material composition of the concrete 
mix B35, W12, $\mathrm{F}_{2} 300, \mathrm{P} 4$. During the calculations, it was assumed that the consumption of cement M500 of JSC Novoroscement amounts to $480 \mathrm{~kg} / \mathrm{m}^{3}$. Consider a massive grillage of the supports of the Crimean bridge with a size of $19,500 \times 10,200 \times 4,000 \mathrm{~mm}$, the diagram of which is shown in Figure 1, the graphs of heating and cooling of concrete, as well as its set of strength are shown in Figure 2.

5100

150,500, $900,900,900,900,850$

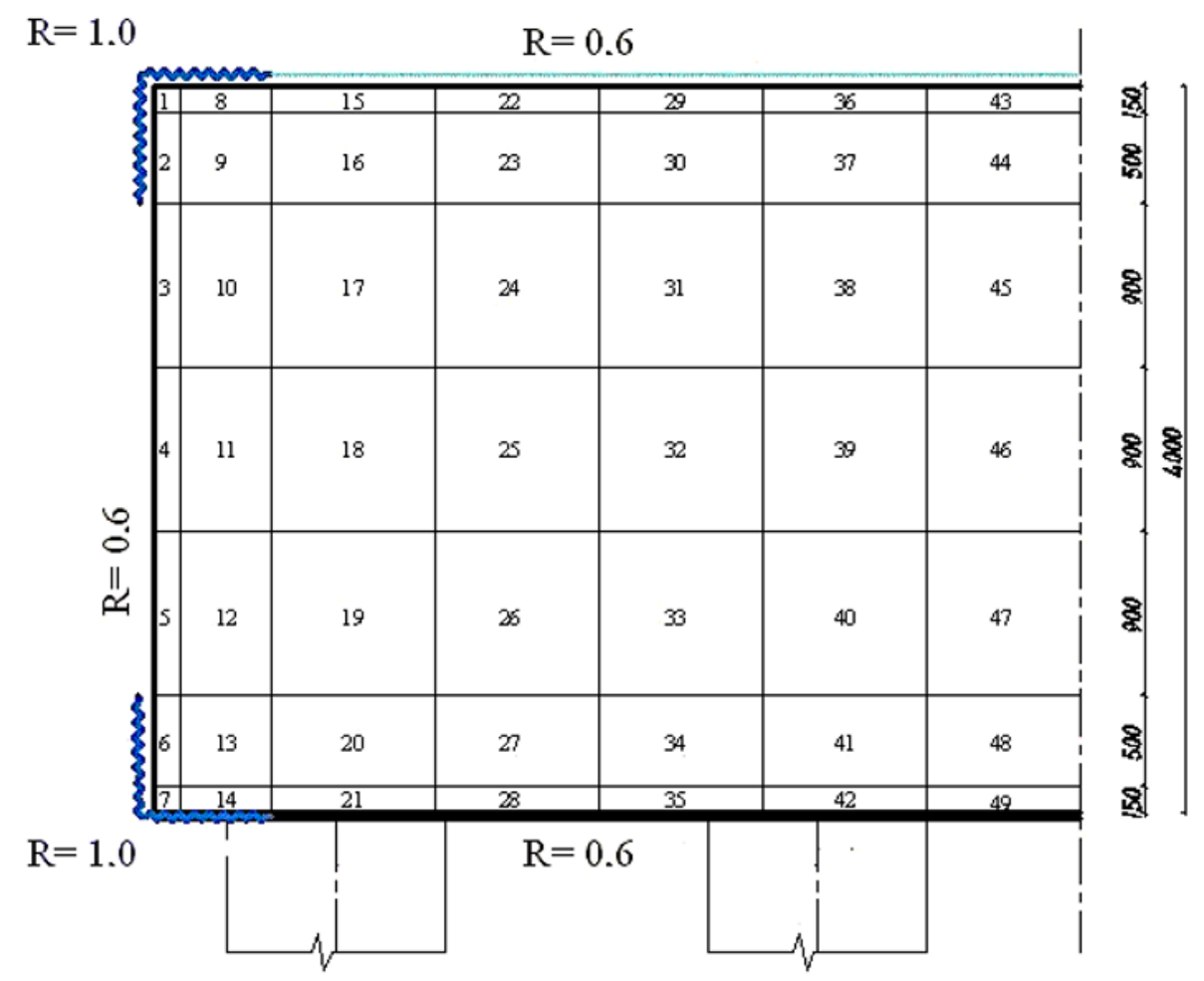

Fig. 1 Graph of foundation frame with size of $19500 \times 10200 \times 4000 \mathrm{~mm}$ 


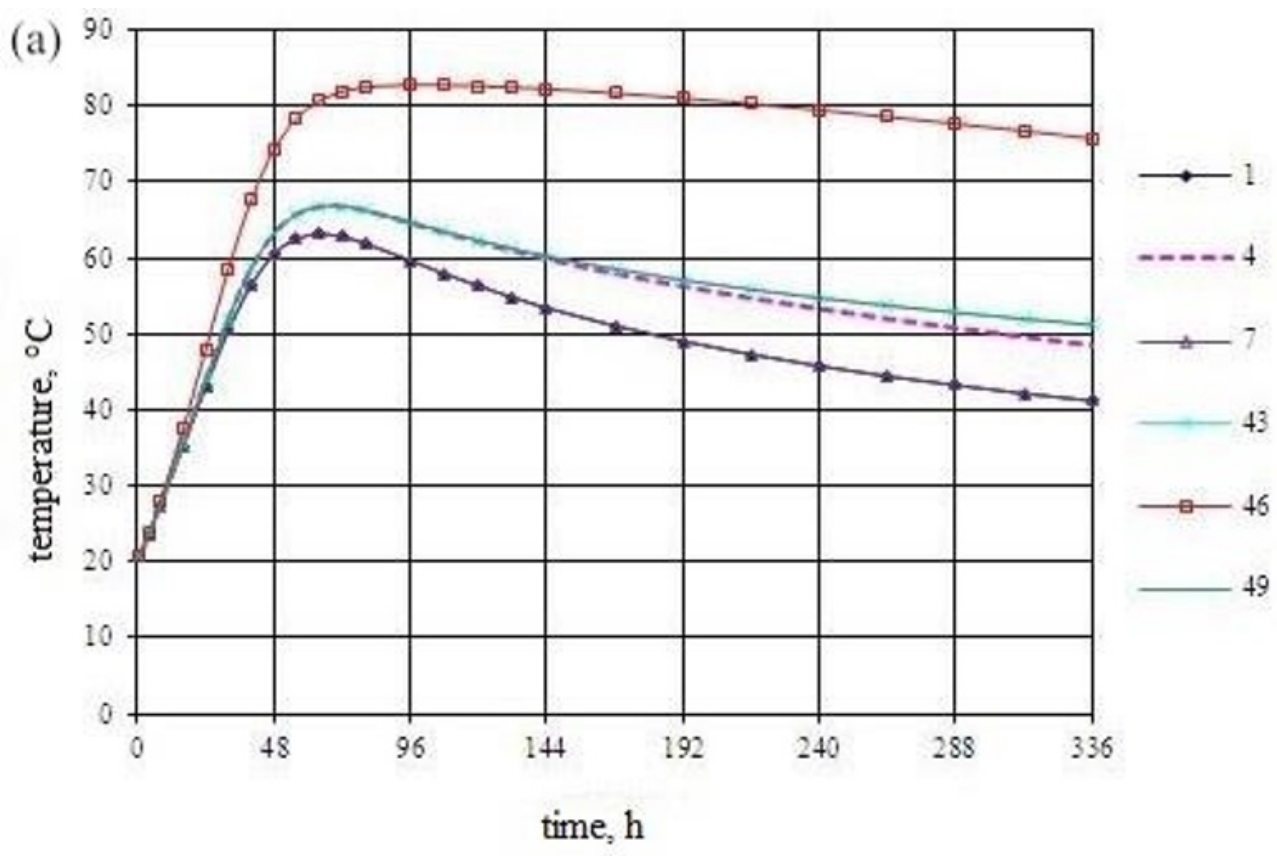

(b)

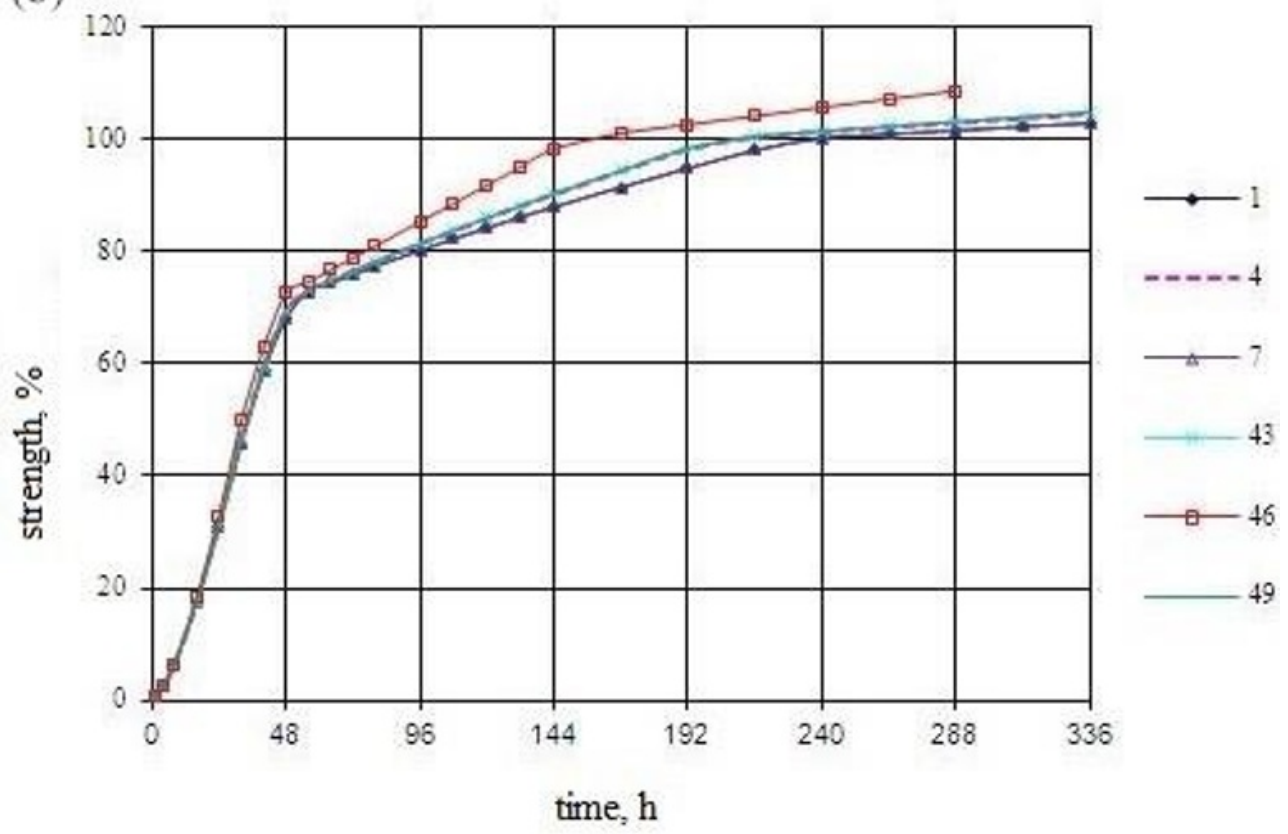

Fig. 2 - Temperature (a) and strength (b) change of foundation frame at the starting temperature of concrete $20^{\circ} \mathrm{C}$ and outside temperature $20^{\circ} \mathrm{C}$

The graphs show that when concrete is kept in the formwork without additional insulation, a large temperature drop is formed and even taking into account the formation of a favorable thermal state of its own, it is impossible to provide the required crack resistance. That's why it is necessary to change the thermal insulation value during 
calculations, ensuring the prevention of cracks. At the same time for this grillage it is obvious that with additional warming of low-mass ribs and edges of the structure, considering the generated temperature field of zero stresses, the allowable difference at maximum heating of the concrete and during the maximum temperature difference exceeds $20^{\circ} \mathrm{C}$, while the concrete curing $75 \%$ of the design is provided three days after concreting.

Now we will consider the rack of the support of the Crimean bridge, whose diagram in the longitudinal direction is shown in Figure 3, the graphs of the heating and cooling of the concrete, as well as its strength gain are shown in in Figure 4.

Based on the data obtained, it is possible to make an analysis that a favorable own thermally stressed state is also formed in the concrete of the structure, however, additional warming of the base perimeter, on which the concrete mix is placed, is necessary to avoid mass outflow of heat from the concrete mix and formation of temperature cracks the joint zone of the laid concrete with the hardened. 


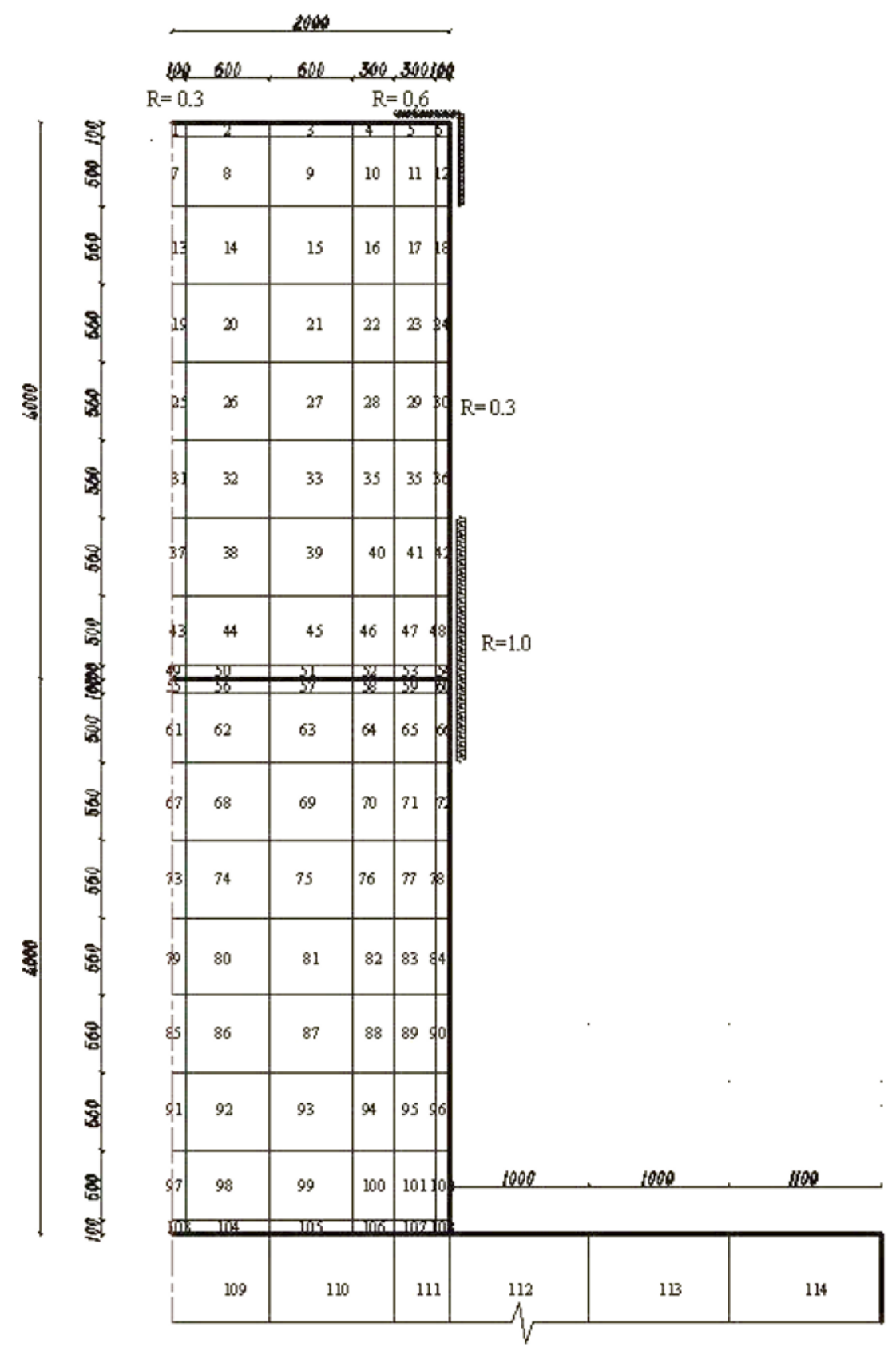

Fig. 3 Graph of pier column of the Crimean bridge lengthwise 

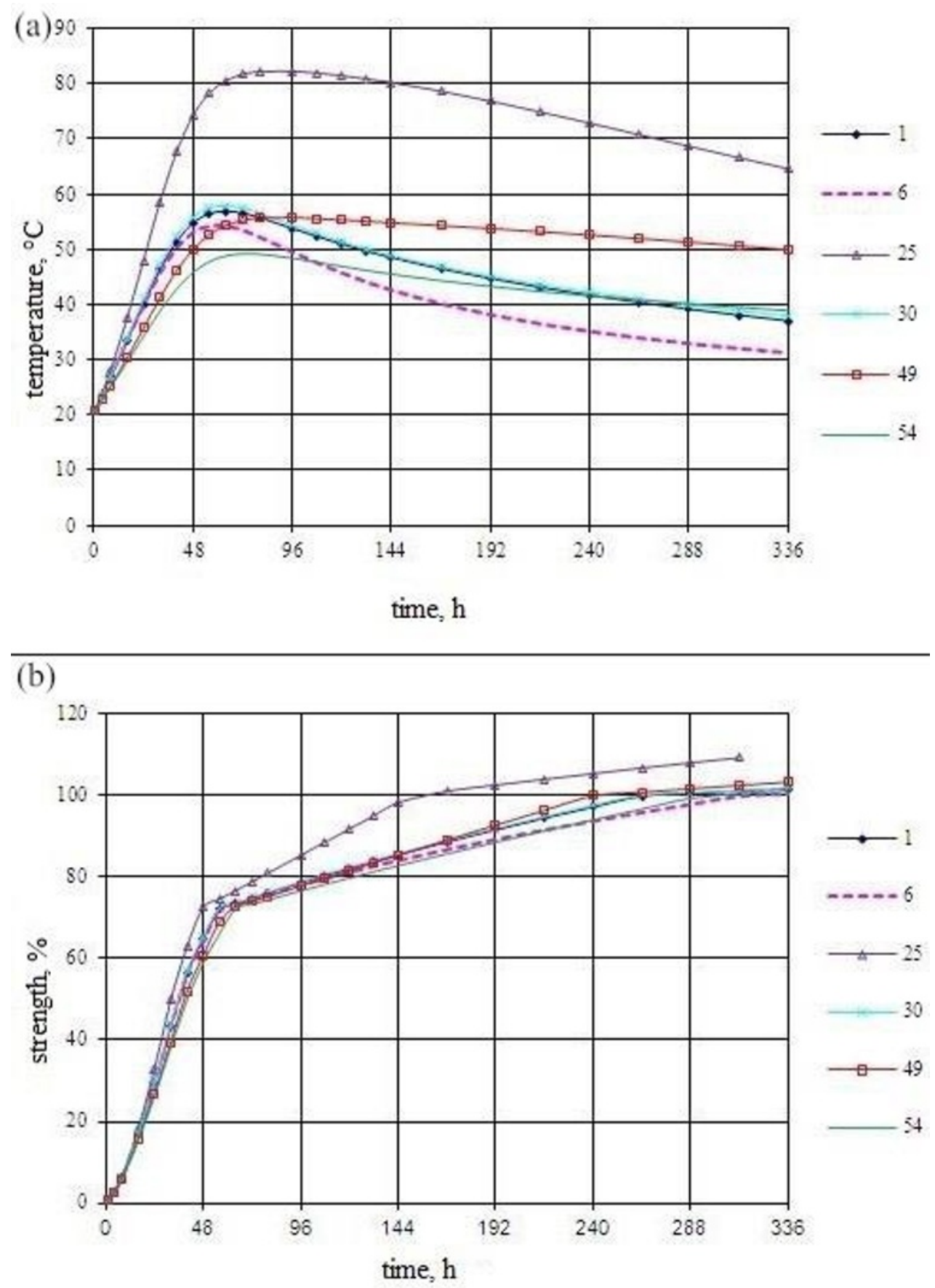

Fig. 4. Temperature (a) and strength (b) change of pier column lengthwise at the starting temperature of concrete of $20^{\circ} \mathrm{C}$ and outside temperature $20^{\circ} \mathrm{C}$

The result of the presented work showed that in the design, when forming a favorable thermal stress-stressed state, the crack resistance of the structure can be ensured while ensuring the required temperature difference, including taking into account the accelerated timing of formwork turnover, which is largely determined by the temperature of the 
previously concreted base, which is laid concrete mix. When carrying out this work, the experience described by the authors of the article previously [19] was applied, according to which a value of $40^{\circ} \mathrm{C}$ was taken for this temperature.

\section{Conclusion}

The work carried out allowed to generalize and clarify the previously obtained conclusions [20 ... 21], as well as to establish the required design parameters of the thermally stressed state of hardening concrete of the bridge, to develop measures to prevent cracking in concrete, taking into account the hot climate. It is also shown in the paper that, as applied to non-class transport structures, one can develop our own approach to the process of concreting, which has a significant impact on the guarantee of obtaining the required consumer properties of the entire structure being erected.

The experience of scientific support for the construction of such objects has proved that the current practice of this support solely at the stage of its construction does not fully justify itself. In order to select efficient materials and construction technologies, scientific support of the object is required to be carried out already at the design stage, which actually turns out to be beneficial both from financial and practical points of view.

Generalized studies of the hardening concrete stress state show that regardless of the features of the structural elements of transport facilities with regard to them, it is possible to develop various technologies for protection against the occurrence of temperature defects, even taking into account the specified rate of construction.

On the basis of the obtained data and generalization of the available experience, the authors of the article developed technological regulations for the production of preparatory, formwork, reinforcement and concrete works. The main provisions of the work allowed to ensure the required rate of concreting of the structural elements of the Crimean bridge while observing the required timing of formwork turnover. This, in particular, made it possible to speed up the process of launching motor traffic on the bridge, set the pace of construction of the railway part of the bridge while strictly complying with the requirements for ensuring high consumer properties of structures and accumulate experience in building such extra-curricular facilities.

\section{References}

1. Kosmin V V and Mozalev S V 2014 Scientific and Technical Journal «Vestnik mostostroyeniya» Problems of research, design and construction of large span bridges vol 1 (Moscow) pp 19-24

2. Krasnovskiy B M 2004 Engineering and physical foundations of winter concreting methods (Moscow: GASIS) p 470

3. Sokolov S B 2002 Influence of air temperature fluctuations in hotbeds on the temperature of hardening concrete during the erection of monolithic slab-ribbed spans during the cold period of the year vol 213 (Moscow: TSNIIS) pp 167-72

4. Passek V V, Zakovenko V V, Antonov E A and Yefremov A N 2002 Application of artificial cooling in the process of controlling the temperature regime of erected reinforced concrete arches vol 213 (Moscow: TSNIIS) pp 73-5

5. Smirnov N V and Antonov E A 2005 The role of creep of concrete in the formation of the thermo-stress state of monolithic reinforced concrete structures in the process of its erection vol 213 (Moscow: TSNIIS) pp 89-117

6. Yevlanov S F 2002 Technological cracks on the surface of monolithic building structures vol 208 (Moscow: TSNIIS) pp 27-36 
7. Vasil'yev A I and Veytsman S G 2015 Scientific and Technical Journal «Vestnik mostostroyeniya» Modern trends and problems of domestic bridge construction vol 1 (Moscow) pp 2-17

8. Solov'yanchik A R, Shifrin S A, Il'in A A and Sokolov S B 2006 Selection of technological parameters for the production of concrete works during the erection of massive grillage and support of the arch bridge of the cable bridge over the Moscow River vol 230 (Moscow: TSNIIS) pp 24-30

9. Solov'yanchik A R, Pulyayev S M and Pulyayev I S 2018 Scientific and Technical Journal «Vestnik SibADI» Investigation of the heat release of cements used in the construction of a bridge across the Kerch Strait vol 2 (Omsk) pp 283-93

10. Solov'yanchik A R, Korotin V N, Shifrin S A and Veytsman S G 2002 Scientific and Technical Journal «Vestnik mostostroyeniya» Experience in reducing cracking in concrete from thermal effects during the construction of the Gagarinsky tunnel vol 3-4 (Moscow) pp 53-9

11. Ginzburg A V 2014 Scientific and Technical Journal «Vestnik MGSU» Ensuring the high quality and efficiency of work in the construction of tunnels from monolithic concrete vol 1 (Moscow: Moscow State University of Civil Engineering Press) pp 98110

12. Solov'yanchik A R, Shifrin S A, Korotin V N and Veytsman S G 2003 Realization of the concept of "quality" in the construction of the Gagarinsky tunnel in Moscow vol 217 (Moscow: TSNIIS) pp 206-12

13. Balyuchik E A, Velichko V P and Chernyy K D 2012 Scientific and Technical Journal «Transportnoye stroitel'stvo» Manufacturing of cladding units during the winter construction of a bridge across the Angara River vol 10 (Moscow) pp 4-7

14. Solov'yanchik A R and Pulyayev I S 2008 Scientific and Technical Journal «Vestnik MGSU» Prevention of cracking in concrete when erecting the lower parts of the pylons of the cable-stayed bridge across the Oka River on the bypass of the city of Murom vol 1 (Moscow: Moscow State University of Civil Engineering Press) pp 285-95

15. Solov'yanchik A R, Shifrin S A, Korotin V N and Veytsman S A 2003 Experience in the use of incomplete compression of concrete to prevent the appearance of cracks in structural elements of transport structures vol 217 (Moscow: TSNIIS) pp 200-5

16. Tarasov A M, Bobrov F Y and Pryakhin D V 2007 Scientific and Technical Journal "Vestnik mostostroyeniya» Application of physical modeling in the construction of bridges and other structures vol 1 (Moscow) pp 21-6

17. Pryakhin D V 2009 Scientific and Technical Journal «Transportnoye stroitel'stvo» Investigation of the cable-stayed bridge structure using physical modeling methods vol 10 (Moscow) pp 11-3

18. Velichko V P and Chernyy K D 2013 Scientific and Technical Journal «Transportnoye stroitel'stvo» The account of the stress-strain state in the team-monolithic bridge supports at the stage of their construction vol 2 (Moscow) pp 11-3

19. Pulyayev I S and Pulyayev S M 2011 Scientific and Technical Journal «Vestnik MGSU» To the question of the maximum temperature of the substrate, at which it is allowed to lay a concrete mixture in the construction of transport facilities vol 2 (Moscow: Moscow State University of Civil Engineering Press) pp 295-304

20. Korotin V N 2002 Scientific and Technical Journal «Vestnik mostostroyeniya» Structurally - technological features of the construction of monolithic bridge structures of the flyover vol 3-4 (Moscow) pp 3-8

21. Passek V V and Solov'yanchik A R 1980 The technique for studying the temperature conditions of the beams of bridge building structures in the process of heat and moisture treatment Moscow: TSNIIS) pp 97-103 